\title{
Intensive Fruit-zone Leaf Thinning Increases Vitis vinifera L. 'Cabernet Sauvignon' Berry Temperature and Berry Phenolics without Adversely Affecting Berry Anthocyanins in Virginia
}

\author{
Cain C. Hickey ${ }^{1}$ \\ Department of Horticulture, University of Georgia, 322 Hoke Smith \\ Building, Athens, GA, 30602
}

Tony K. Wolf

Alson H. Smith, Jr. Agricultural Research and Extension Center, Virginia Tech, 595 Laurel Grove Road, Winchester, VA 22602

Additional index words. anthocyanins, canopy management, fruit exposure, grape temperature, leaf removal

\begin{abstract}
Selective leaf removal in the proximity of grape clusters is a useful practice to manage fruit diseases and otherwise improve fruit composition. The current recommendation in the eastern United States is to create a fruit zone with one to two leaf layers and to focus removal on the "morning sun" side of the canopy. We evaluated a more intense and an earlier application of fruit-zone leaf thinning relative to current recommendations to determine whether additional benefits could be obtained without a penalty of impaired berry pigmentation or other ill effects of abundant grape exposure. Fruit secondary metabolites and berry temperature were monitored in two different field experiments conducted with 'Cabernet Sauvignon' in the northern Shenandoah Valley American Viticultural Area (AVA) of Virginia. One experiment evaluated the effects of no leaf removal, prebloom removal of four basal leaves per shoot, and prebloom removal of eight basal leaves per shoot. The other experiment evaluated the effects of no leaf removal and postfruit set removal of six basal leaves per shoot. On average, exposed grapes heated to $\geq 30{ }^{\circ} \mathrm{C}$ for a $126 \%$ longer period ( 53 hours) than shaded grapes in the postveraison period (from color development through harvest). However, postveraison grape temperatures did not remain above provisional, critical temperature thresholds of either 30 or $35{ }^{\circ} \mathrm{C}$ for as long as they did in studies conducted in sunnier, more arid climates. There were minimal differences in berry temperature between east- and westexposed grapes in the northeast/southwest-oriented rows of the experimental vineyard. Regardless of implementation stage, leaf removal consistently increased total grape phenolics measured spectrophotometrically, and either increased or had no impact on anthocyanins relative to no leaf removal. Grape phenolics and anthocyanins were unaffected by canopy side. Berry total phenolics were increased and anthocyanins were at least maintained in fruit zones void of leaf layers - a canopy attribute that reduces bunch rot in humid regions.
\end{abstract}

Fruit-zone leaf removal is a useful cultural practice to help manage grape diseases (Austin and Wilcox, 2011; English et al., 1989; Hed et al., 2015; Wolf et al., 1986). The

Received for publication 24 Jan. 2019. Accepted for publication 11 Apr. 2019.

We gratefully acknowledge funding for this work from the Virginia Wine Board, Virginia Agricultural Council, and the National Institute of Food and Agriculture, U.S. Department of Agriculture, under agreement no. 2010-51181-21599.

We extend our appreciation to Rachael White, Trevor Wolf, Danielle Bunce, Dana Melby, Brycen Hill, Hannah Kasabian, and Tremain Hatch for their collective vineyard and laboratory assistance. 'Corresponding author. E-mail: vitis@uga.edu. increased fruit exposure can also lead to increased concentrations of compounds that are associated positively with red wine quality potential (Hunter et al., 1991; Razungles et al., 1998; Smart and Robinson, 1991; Verzera et al., 2016) and decreased levels of compounds that reduce red wine quality potential (Ryona et al., 2008). The studies cited confirmed collectively that fruit-zone best management practice was to expose grape clusters highly, without a "penalty" to fruit or wine quality if more than $60 \%$ of grape clusters were exposed (Smart and Robinson, 1991). However, research conducted in the western United States during the early 21 st century has motivated fruitzone leaf removal practice to become more conservative and implemented selectively on the morning-sun canopy side, primarily because of high-temperature-driven anthocyanin reduction in highly exposed grapes, especially on afternoon-sun canopy sides (Bergqvist et al., 2001; Spayd et al., 2002; Tarara et al., 2008). Similar practices were adopted subsequently in humid eastern U.S. vineyards, where grape cluster coverage by an average of one to two leaf layers of covering is recommended (Reynolds and Wolf, 2008). Current best management practice maintains a more shaded fruit zone, particularly on the afternoon-sun side of the canopy, than that recommended previously-more than 25 years ago (Smart and Robinson, 1991).

Fruit exposure increased anthocyanins in Canada (Di Profio et al., 2011; Staff et al., 1997), Spain (Diago et al., 2012), and Greece (Kotseridis et al., 2012). Recent work in Michigan (Frioni et al., 2017) and northern Virginia (Hickey et al., 2018) found that removal of six basal leaves from primary shoots increased or maintained grape anthocyanin and phenolic levels in Cabernet franc. It is worth questioning the validity of current fruit-zone management recommendations in the eastern United States because it appears radiation benefits grape anthocyanins across a wide range of growing conditions and cultivars. Moreover, increasing radiation penetration into the fruit zone is well aligned with optimal bunch rot management (English et al., 1989), particularly in humid growing regions (Hickey and Wolf, 2018).

Grapes from a red-fruited cultivar remained green when grown in the dark (Weaver and McCune, 1960) and even grapes exposed to low light conditions had reduced color development (Dokoozlian and Kliewer, 1996). Light is necessary for anthocyanin biosynthesis (Takos et al., 2006), particularly if uncoupled from temperature extremes (Spayd et al., 2002; Tarara et al., 2008) The daily light integral, the average daily photo synthetic photon flux density, is less throughout the ripening period (and anthocyanin accumulation period) in grapegrowing regions of the eastern United States relative to the arid grape-growing regions of the western United States (Faust and Logan, 2018). Furthermore, it is generally cloudier in the humid eastern United States relative to arid regions of the western United States (NASA Earth Observations, 2018). Clouds, particularly low stratocumulus clouds, have an overall net cooling effect on Earth's surface (NASA, 1999). Exposed grape clusters in the eastern United States may experience less radiant heating and therefore have at least maintained, if not increased, anthocyanin concentrations relative to exposed grape clusters in arid regions of the western United States.

We hypothesized that aggressive prebloom and postfruit set fruit-zone leaf removal would increase fruit-zone radiation penetration and increase grape temperature modestly, and thus have negligible negative impacts on grape metabolites important for 
red wine quality relative to grapes from shaded fruit zones. As part of a larger experiment that evaluated leaf removal effects on crop yield, disease incidence, and primary fruit composition (Hickey and Wolf, 2018), the current study reports on berry temperature patterns and grape phenolics and anthocyanins.

\section{Materials and Methods}

\section{Experimental vineyard and treatments}

These experiments used 'Cabernet Sauvignon' ENTAV-INRA ${ }^{\circledR}$ clone 337 vines grafted onto 420-A rootstock and grown at Virginia Tech's Alson H. Smith, Jr. Agricultural Research and Extension Center near Winchester, VA (lat. $39^{\circ} 11^{\prime} \mathrm{N}$, long. $\left.78^{\circ} 28^{\prime} \mathrm{W}\right)$. Vines were planted in May 2006 in rows running generally northeast/southwest $\left(39 / 219^{\circ}\right)$ at a $3.0-\mathrm{m}$ (row) $\times$ $1.5-\mathrm{m}$ (vine) spacing and were trained to bilateral cordons with vertical shoot positioning (VSP). The soil was classified as a Frederick-Poplimento sandy loam (National Resources Conservation Service, 1987); however, a detailed examination of the soil in 2013 reinterpreted it as a closely related series, Poplimento-Hagerstown sandy loam (A. Blackburn, personal communication, 2013). The interrow groundcover, established in 2001, initially comprised a mixture of orchard grass (Dactylis glomerata) and tall fescue ( $F$. arundinacea), cv. Shenandoah, with the fescue dominating after about 6 years. Weekly review of fruit zones was conducted as needed to maintain treatment integrity throughout each growing season.

Two field experiments were conducted: one that evaluated prebloom leaf thinning (2013-15) and one that evaluated postfruit set leaf thinning in 2014 and 2015. Treatments were applied in a randomized complete block design and were replicated six times in both trials. Experimental units were single vines for the prebloom and two vines for the postfruit set trial. Treatments were as described in the following paragraphs.

Prebloom leaf removal experiment (2013-15). Prebloom zero leaves or lateral shoots removed (PB-NO), prebloom removal of leaves and lateral shoots from primary shoot nodes 1 to 4 (PB-4) at modified Eichhorn and Lorenz (EL) growth stage 17 (individual flowers well separated) (Dry and Coombe, 2004), and prebloom removal of leaves and lateral shoots from primary shoot nodes 1 to 8 (PB-8) at modified EL stage 17. All prebloom leaf removal treatments were implemented within the same five-vine experimental units over three seasons (201315). PB-NO was implemented on the same vine in each experimental unit replicate in each season. PB-4 and PB-8 were each implemented on one vine in each experimental unit replicate in 2013; however, PB-4 and PB-8 were implemented consistently on one vine in each experimental unit replicate over 2014 and 2015, which were different vines than those used originally in 2013.

Postfruit set leaf removal experiment (2014 and 2015). Postfruit set zero leaves/ lateral shoots removed (PFS-NO) and postfruit set removal of leaves and lateral shoots from primary shoot nodes 1 through 6 (PFS6) at modified EL stage 29 (peppercorn-size berries) (Dry and Coombe, 2004).

\section{Fruit-zone architecture.}

Point quadrat analysis (Smart and Robinson, 1991) data were collected between modified EL stages 33 (hard, green berries) and 35 (veraison) in each season. A thin metal rod was inserted into the fruiting zone along the transverse axis of the canopy. This process was repeated 10 times in each vine (one insertion every $0.15 \mathrm{~m}$ of row) to quantify fruit-zone leaf layer number (LLN), the number of leaves contacted by the rod as it passed through the fruit zone. Photosynthetically active radiation $(P A R)$ was assessed by inserting a ceptometer (model PAR-80; Decagon Devices, Inc., Pullman, WA) inside canopy fruit zones parallel to and directly above the cordon, and orienting the light interception side of the ceptometer in three different directions $\left(45^{\circ}\right.$ east, vertical, $45^{\circ}$ west); those three readings were then averaged. Two $P A R$ readings (each reading a composite of the three orientations just described) were taken in every vine between 1030 and $1400 \mathrm{HR}$ (daylight savings time, here and throughout article) under consistent ambient radiation conditions. The $P A R$ and LLN data were used to generate cluster exposure flux availability (CEFA), the average $P A R$ that reached grape clusters, using enhanced point quadrat analysis software (EPQA version 1.6.2) (Meyers and Vanden Heuvel, 2008).

\section{Manually measured berry temperature}

The temperature of east- and westexposed berries was measured from 0900 to $1030 \mathrm{HR}$ (morning), at noon (1245-1415 HR), and from 1545 to $1715 \mathrm{HR}$ (afternoon) on select postveraison dates in 2013 (29 Aug. and 24 Sept.), 2014 (20 Aug., 28 Aug., 4 Sept., 16 Sept.), and 2015 (25 Aug. and 8 Sept.). The temperature of three berries on clusters' exterior faces were measured on two randomly selected clusters borne on opposite cordons of one vine - a total of six berry temperature measurements per canopy side per experimental unit, three times per day. Berry temperature was measured by inserting a minihypodermic thermocouple (model HYP1/2; Omega Engineering, Stamford, CT) beneath the skins of berries and recording using a handheld digital thermometer (model HH 25, Omega Engineering).

\section{Automated berry temperature, ambient temperature, and ambient and fruit-zone radiation logging}

One vine of each prebloom leaf removal treatment, from one experimental replicate, was used to $\log$ berry temperature and fruit zone $P A R$. In addition to leaf removal treatment-specific measurements, ambient temperature and $P A R$ were logged immediately surrounding and above the "data logger vine panel," respectively. The temperature of two outside-facing berries on the east and west canopy sides of each leaf removal treatment were measured with a minihypodermic thermocouple (type T, model HYP1/ 2; Omega Engineering) inserted about $0.6 \mathrm{~cm}$ beneath the berry skins and affixed with a strong all-purpose glue. Fruit-zone $P A R$ was measured with a quantum sensor bar (SQ316; Apogee Instruments, Logan, UT) placed on top and parallel to the orientation of one cordon in each leaf removal treatment. Ambient $P A R$ was measured with a quantum sensor bar (SQ316; Apogee Instruments) mounted level at about $3 \mathrm{~m}$ above the ground $(\approx 0.6 \mathrm{~m}$ above vine canopies) at the middle of the experimental replicate where data logging occurred. Ambient temperature was measured with two thermistors (ST100; Apogee Instruments). The thermistors were placed on the north- and south-bordering ends $(\approx 7.6 \mathrm{~m}$ apart) of the "data logger vine panel" and were mounted at fruit-zone height inside a vented radiation shelter. Thermocouples were logged with a solid-state multiplexer (AM25T; Campbell Scientific, Logan, UT) attached to a data logger (CR1000; Campbell Scientific), which also logged the $P A R$ and ambient temperature data.

The following measurements were logged at specified intervals in one vine of each treatment:

2013: Berry and ambient temperature, and fruit-zone $P A R$ were logged at 15-min intervals from modified EL stage $35(50 \%$ veraison) (Dry and Coombe, 2004) on 21 Aug. 2013 through EL 38 (harvest) (Dry and Coombe, 2004) on 9 Oct. 2013.

2014: Berry and ambient temperature, and fruit-zone and ambient $P A R$ were logged at 15-min intervals from modified EL stage 35 (50\% veraison) on 24 Aug. 2014 through 4 Sept. 2014, and at 1-min intervals from 4 Sept. 2014 through modified EL stage 38 (harvest) on 16 Oct. 2014.

2015: Berry and ambient temperature, and fruit-zone and ambient $P A R$ were logged at 1-min intervals from modified EL stage 35 (50\% veraison) 12 Aug. 2015 through modified EL stage 38 (harvest) on 5 Oct. 2015.

\section{Missing postveraison observations}

Data logging was interrupted and $\approx 25 \%$ of daily logged data was lost in 2014 and $29 \%$ was lost in 2015. Missing berry temperature data were estimated using ambient air temperature data recorded at 15 -min intervals with a temperature/humidity probe (CS215L; Campbell Scientific) housed within a vented radiation shelter and logged with a data logger (CR2000X, Campbell Scientific) located about $65 \mathrm{~m}$ from the experimental vineyard panel. Missing berry temperature data were quantified using a multiplier that was applied to the corresponding ambient air temperature data. That multiplier was derived from the recorded average hourly quotient of berry temperature and ambient air temperature for each treatment and canopy side (e.g., berry temperature of $27.0^{\circ} \mathrm{C}$ at an ambient air temperature of $26.5{ }^{\circ} \mathrm{C}=1.02$ 
Table 1. Prebloom and postfruit set leaf removal effect on fruit-zone leaf layer number (LLN) and cluster exposure flux availability (CEFA) at veraison from 2013 to 2015 .

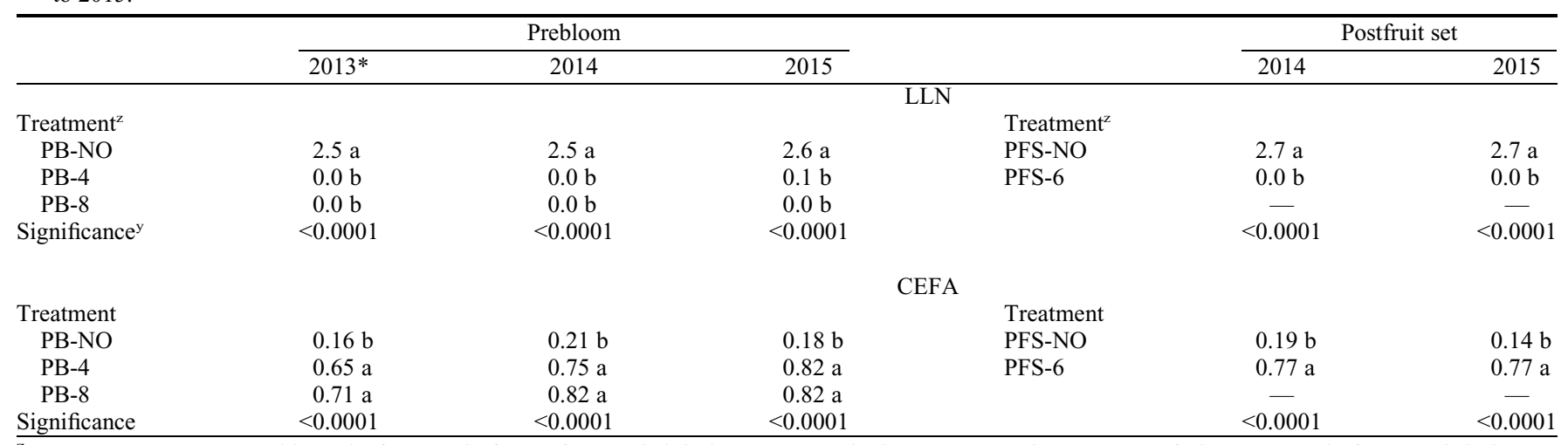

${ }^{\mathrm{z}}$ PB-NO, PB-4, PB-8 = prebloom leaf removal of zero, four, and eight leaves, respectively; PFS-NO and PFS-6 = postfruit set removal of zero and six leaves, respectively.

${ }^{\mathrm{y}}$ Significance of treatment effects. Means in the same treatment group (columns) not sharing the same letter are significantly different at the 0.05 level based on adjusted $P$ values using Tukey's honestly significant difference test (prebloom experiment) and Student's $t$ test (postfruit set experiment).

Table 2. Leaf removal, canopy side, and time-of-day effect on average manual berry temperature measurements on select dates during the postveraison periods from 2013 to 2015 .

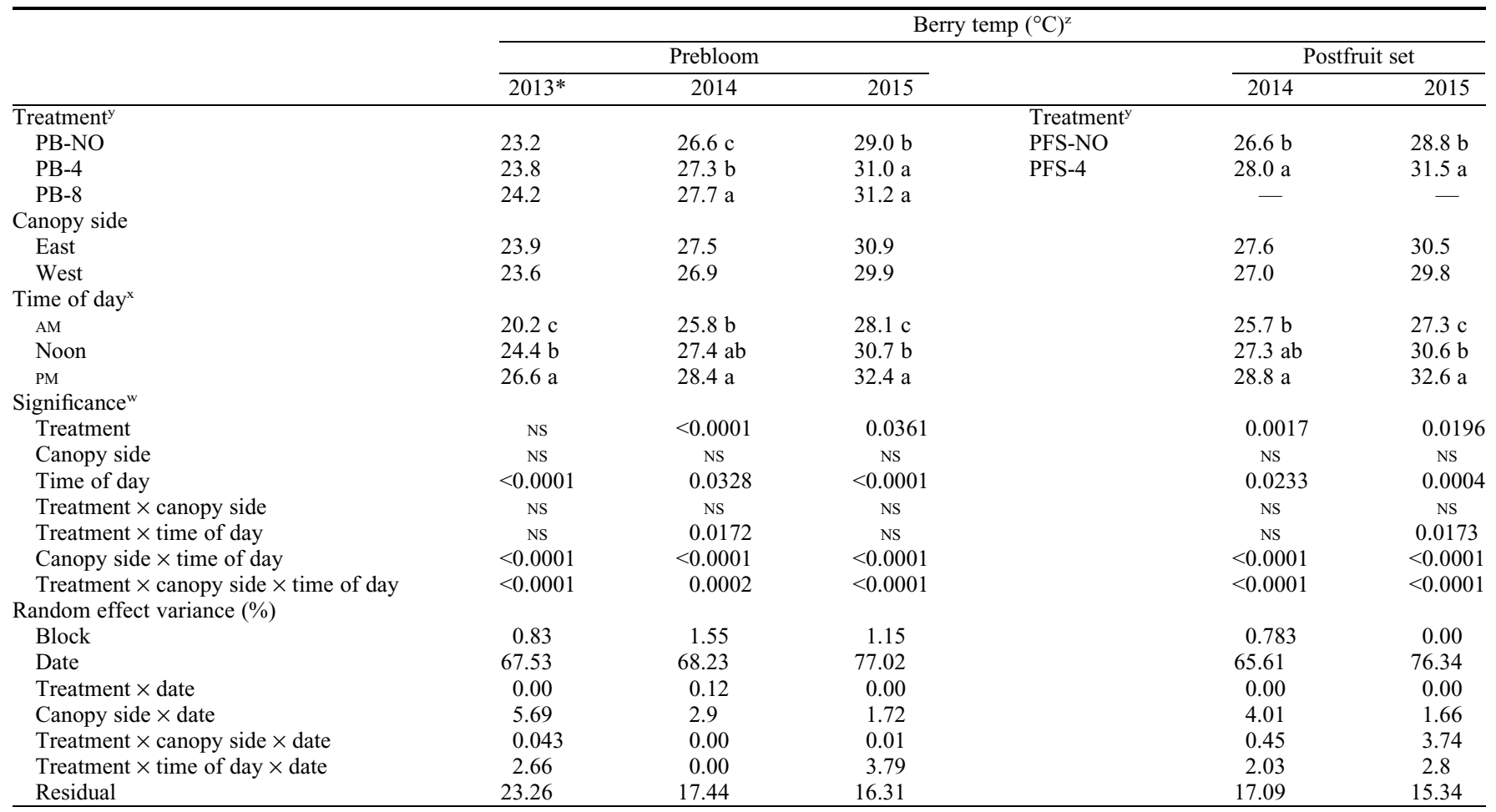

${ }^{\mathrm{z}}$ Berry temperature collected in 2013 (29 Aug. and 24 Sept.), 2014 (20 Aug., 28 Aug., 4 Sept., and 16 Sept.), and 2015 (25 Aug. and 8 Sept.).

${ }^{\mathrm{y}} \mathrm{PB}-\mathrm{NO}, \mathrm{PB}-4, \mathrm{~PB}-8=$ prebloom leaf removal of zero, four, and eight leaves, respectively. PFS-NO and PFS- $6=$ postfruit set removal of zero and six leaves, respectively.

${ }^{\mathrm{x}}$ Time of day references the following time spans: AM $=900-1030 \mathrm{HR}$; Noon $=1245-1415 \mathrm{HR}$; PM $=1545-1715 \mathrm{HR}$.

${ }^{\mathrm{w}}$ Significance of treatment effects (NS = not significant). Means in the same treatment group (columns) not sharing the same letter are significantly different at the 0.05 level based on adjusted $P$ values using Tukey's honestly significant difference test (prebloom experiment, time of day) and Student's $t$ test (postfruit set experiment, canopy side).

multiplier) in each respective month of missing observations. The missing sum of hours that berry temperature was estimated to be greater than 30 or $35^{\circ} \mathrm{C}$ was summed with recorded observations; those data are presented by treatment and canopy side in the Results section.

Hourly time denotes the average of the hour of time that occurred thereafter (e.g., $1300 \mathrm{HR}=$ average temperature/radiation over 1300-1359 HR). All specific times and time frames are reported in daylight savings time, as mentioned earlier.

\section{Meteorology, dormant cane pruning} weight, Botrytis bunch rot incidence, crop yield components, cluster compactness, and primary chemistry

Meteorology has been reported previously (Hickey and Wolf, 2018). In general, seasonal growing degree day accumulation in 2015 was greater than in 2013 and 2014, and seasonal rainfall was $25 \%$ greater in 2013 compared with the 2014 and 2015 seasons (data not shown). Crop yield data from the 2013 prebloom leaf removal experiment, and 2014 and 2015 of the postfruit set leaf removal experiment have been reported previously (Hickey and Wolf, 2018). In 2014 and 2015, prebloom leaf removal treatments reduced crop yield compared with no leaf removal in a similar fashion to previously reported prebloom leaf removal effects on 

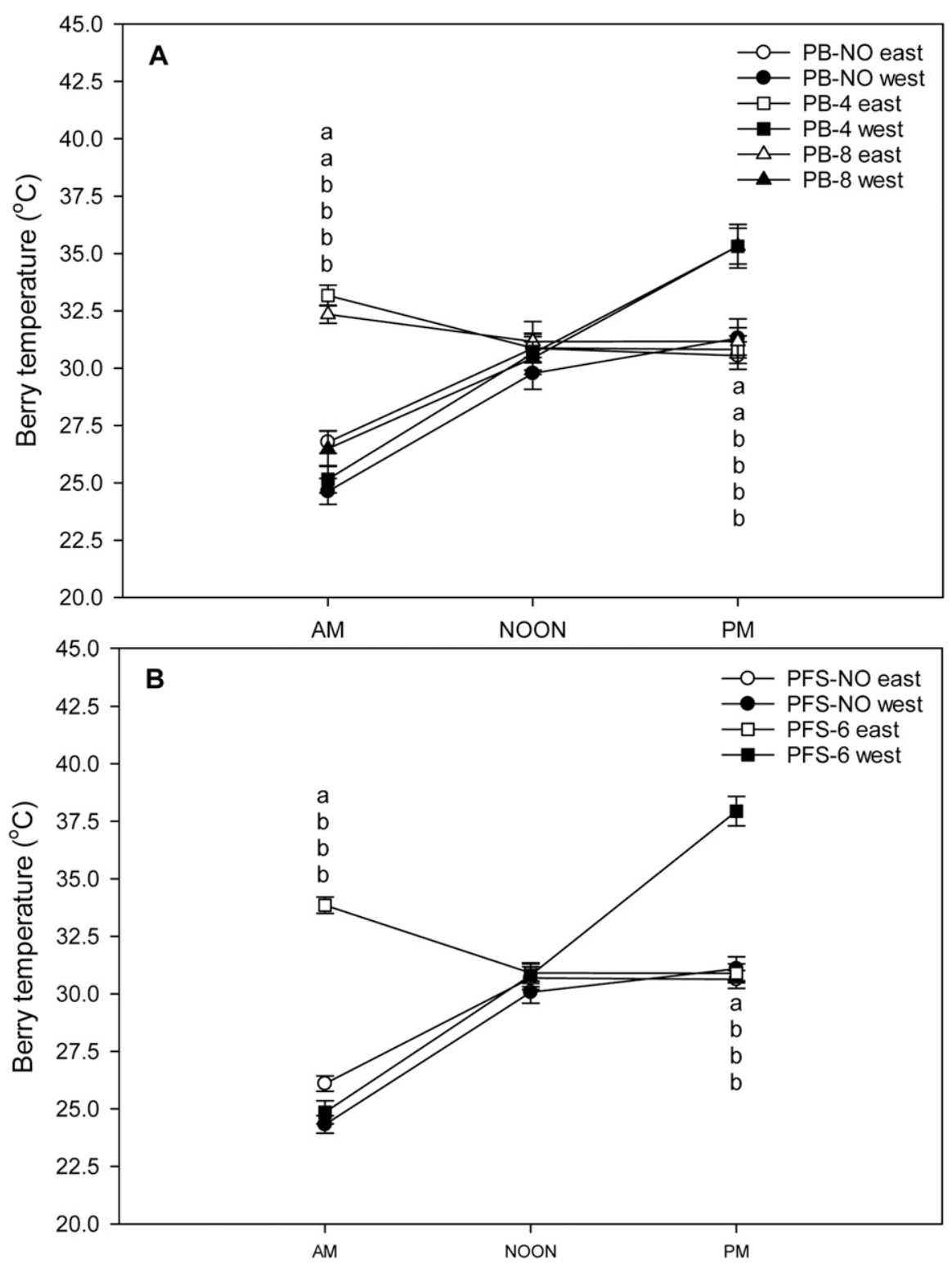

Fig. 1. The effect of $(\mathbf{A})$ prebloom and $(\mathbf{B})$ postfruit set leaf removal on east- and west-exposed berries at three different times of day in 2015. PB-NO, PB-4, and PB-8, prebloom removal of zero, four, and eight leaves, respectively; PFS-NO and PFS-6, postfruit set removal of zero and six leaves, respectively; $\mathrm{AM}=900-1030$ HR; $\mathrm{NOON}=1245-1415 \mathrm{HR}$; PM $=1545-1715$ HR. Means within the same time of day not sharing the same letter are significantly different $(0.05)$, and means within the same time of day without letters are not significantly different, using Tukey's honestly significant difference test (0.05). Error bars are $\pm \mathrm{SE}$. Data points are means of six replicates recorded on each of two dates (25 Aug. and 8 Sept.).

crop yield (Hickey and Wolf, 2018) (data not shown). Besides an inconsistent decrease in total juice titratable acidity (TA), prebloom leaf removal had unremarkably affected primary fruit composition in 2014 (Brix range, 20.8-22.2; TA range, 6.11-9.09 $\mathrm{g} \cdot \mathrm{L}^{-1}$ across treatments) and 2015 (Brix range, 20.8-22.7; TA range, 6.08-9.18 g. $\mathrm{L}^{-1}$ across treatments) (data not shown).

\section{Spectrophotometric estimation of total grape phenolics and anthocyanins}

Immediately before harvest in 2013 (just prebloom experiment), 2014, and 2015 (both experiments), 60-berry samples were collected randomly from both the east and west canopy sides of each experimental unit and
Scientific Inc., Pittsburgh, PA), and the absorbance at 520 and $700 \mathrm{~nm}$ was measured in duplicate with a Genesys 8 ThermoSpectronic spectrophotometer (Cambridge, UK). The KCl-buffered sample ( $\mathrm{pH} 1.0)$ was diluted further (2 parts sample: 1 part $0.025 \mathrm{M} \mathrm{KCl}$ buffer ratio) and its 280-nm absorbance was measured in duplicate to quantify phenolics. Total phenolics were expressed on an absorbance unit-per-gram-berry basis, and anthocyanins on a milligram-per-gram-berry basis using the molecular weight (493.2) and molar extinction coefficient $(28,000)$ of malvidin-3glucoside.

\section{Statistical analysis}

JMP Pro version 13 (SAS Institute, Cary, NC) was used for statistical computation. A mixed model was used to evaluate the random block effect and fixed treatment effect for EPQA and berry phenolics and anthocyanins. Canopy side and treatment interaction with canopy side were added to the model to evaluate berry phenolics and anthocyanins. Treatment, canopy side, date (random effect), and their interactions were evaluated with berry temperature data. Data from each experiment were analyzed separately. Significant mean separation $(\alpha \leq 0.05)$ was determined with Tukey's honestly significant difference test for the prebloom leaf removal experiment and for "time of day" when analyzing manually recorded berry temperatures. Student's $t$ test was used to determine mean separation $(\alpha \leq 0.05)$ for the postfruit set leaf removal experiment and for "canopy side" effects. Linear regressions were used to evaluate the relationship between harvest berry weight and EPQA metrics with total berry phenolics and anthocyanins.

\section{Results and Discussion}

Fruit-zone architecture. Leaf removal resulted in zero fruit-zone LLNs at veraison whereas no leaf removal resulted in a range of 2.5 to 2.7 LLN at veraison across both experiments (Table 1). Leaf removal treatments consequently led to fewer fruit-zone LLN, whereas no leaf removal resulted in slightly greater fruit-zone LLN relative to the current recommendations of one to two LLNs in eastern North America (Reynolds and Wolf, 2008). Prebloom and postfruit set leaf removal resulted in at least a 3-fold, and sometimes greater than 4-fold, increase in fruit-zone CEFA compared with no leaf removal. Similar increases in fruit zone CEFA have been reported when basal removal of six leaves was compared with no leaf removal in Cabernet franc and Petit Verdot (Hickey et al., 2018). It may therefore be assumed that a fruit zone void of leaf layers affords a 3 - to 4-fold increase in fruit-zone CEFA values relative to fully foliated fruit zones.

Manually measured berry temperature. The significant three-way interaction of treatment $\times$ canopy side $\times$ time of day (Table 2 ) revealed 1) eastside and westside berry temperature was relatively greater in all leaf removal treatments compared with no removal 


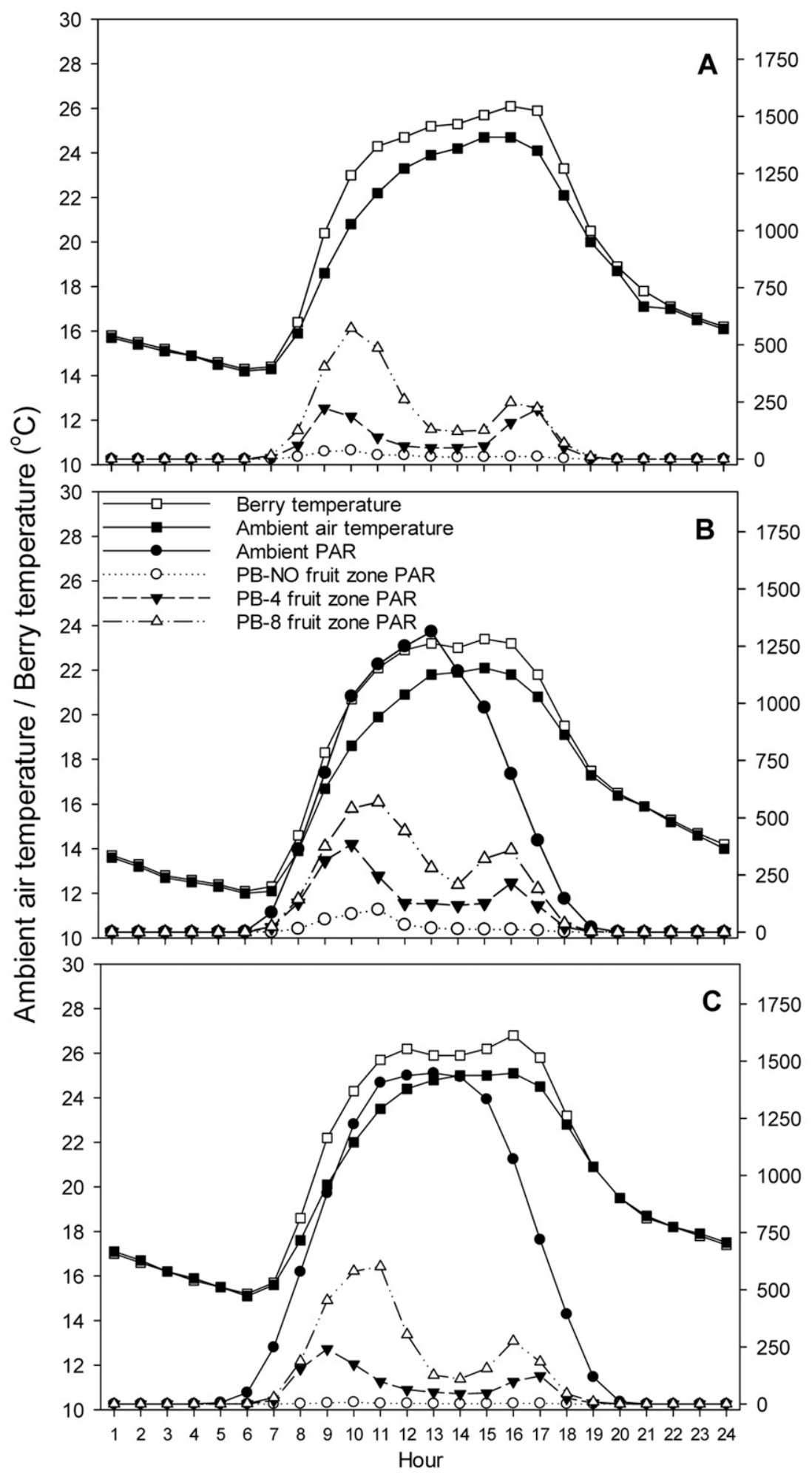

Fig. 2. Diurnal patterns of mean berry temperature, ambient air temperature, ambient photosynthetically active radiation $(P A R)$, and fruit-zone $P A R$. Berry temperature is an average of records in PB-NO, PB4, and PB-8 prebloom removal of zero, four, and eight leaves, respectively) plots. (A) Data recorded 21 Aug. to 9 Oct. 2013. (B) Data recorded 24 Aug. to 16 Oct. 2014. (C) Data recorded 12 Aug. to 5 Oct. 2015. Note: Ambient PAR was not measured in 2013.

in the morning and afternoon (Fig. 1), respectively, and 2) there were limited treatment differences in berry temperature at noon (when the sun was above the canopy) and when berry temperature was measured on the east side in the afternoon and the west side in the morning (Fig. 1; 2013 and 2014 data not shown). Similar three-way interactions have been reported previously for manually measured berry temperature in our related study (Hickey et al., 2018). Fruit exposure extent, time of day, and canopy side all affected diurnal berry temperature patterns, as shown previously in the San Joaquin Valley in California (Bergqvist et al., 2001). The significant two-way canopy side $\times$ time of day interaction (Table 2) revealed that 1) eastside berry temperature was greater than westside berry temperature in the morning, 2) westside berry temperature was greater than eastside berry temperature in the afternoon, and 3) there was no difference between eastside and westside berry temperature at noon (data not shown).

Average (Table 2) and maximum (data not shown) berry temperatures were greater when leaves were removed from fruit zones compared with no leaf removal, albeit inconsistently across years. Berry temperature was greater in the afternoon than at noon, and greater at noon than in the morning. Although greater maximum berry temperatures were measured manually on the west side relative to east side of the canopy in 2013 and 2015 (data not shown), our manually measured average berry temperature data showed that the west side was not warmer than the east side when averaged across morning, noon, and afternoon (Table 2). Our recorded temperature differentials between east and west canopy sides are less dramatic than those reported from similarly oriented vine rows in the western United States (Bergqvist et al., 2001; Spayd et al., 2002; Tarara et al., 2008).

Evaluation of random effect contributions during the analysis of variance illustrated that measurement date had the greatest impact on berry temperature (Table 2); however, berry temperature was measured manually on only a handful of days and without regard to the consistency of meteorological consistency across those days. Automated logging may be the only reliable method to characterize berry temperature in the eastern United States, as modeling berry temperature in humid regions would be difficult as a result of variable cloud cover (Cola et al., 2009).

Automated ambient temperature, ambient and fruit-zone radiation, and berry temperature logging. Berry temperature was not logged in the postfruit set leaf removal plots. It was hypothesized that berry temperatures in postfruit set leaf removal plots would be similar to those in the prebloom leaf removal plots given the similarities in fruit zone LLN (Table 1) and manually recorded berry temperatures (Table 2) in prebloom and postfruit set plots. Average ambient air temperature was greater during the postveraison periods of $2013\left(19.5^{\circ} \mathrm{C}\right)$ and 2015 $\left(21.4{ }^{\circ} \mathrm{C}\right)$ compared with $2014\left(16.9{ }^{\circ} \mathrm{C}\right)$. Furthermore, ambient air temperature was greater from 1500 to $1700 \mathrm{HR}$ (23.7 to $24.5{ }^{\circ} \mathrm{C}$ ) relative to the 0900 to $1100-\mathrm{HR}$ time frame $\left(19.3\right.$ to $\left.22.3{ }^{\circ} \mathrm{C}\right)$ over 3 years (Fig. 2). Diurnal ambient $P A R$ trends were bell shaped. However, in contrast to ambient air temperature, ambient $P A R$ was greater from 0900 to $1100 \mathrm{HR}$ relative to the 1500 to 1700-HR time frame. When averaged across 2014 and 2015, ambient PAR ranged from 810 to $1288 \mu \mathrm{mol} \cdot \mathrm{m}^{-2} \cdot \mathrm{s}^{-1}$ over 0900 to 1100 HR and 560 to $1157 \mu \mathrm{mol} \cdot \mathrm{m}^{-2} \cdot \mathrm{s}^{-1}$ over 1500 
Table 3. Total hours that berry temperature was recorded $\geq 30$ or $35^{\circ} \mathrm{C}$ on east and west canopy sides, and comparative percentage of time split between canopy sides, in prebloom leaf removal plots over the $2013-15$ postveraison periods.

\begin{tabular}{|c|c|c|c|c|c|c|}
\hline \multirow[b]{2}{*}{ Treatment ${ }^{z}$} & \multicolumn{2}{|c|}{$2013^{y}$} & \multicolumn{2}{|c|}{$2014^{y, x}$} & \multicolumn{2}{|c|}{$2015^{y x}$} \\
\hline & East (h, \%) & West (h, \%) & East (h, \%) & West (h, \%) & East (h, \%) & West $(\mathrm{h}, \%)$ \\
\hline & \multicolumn{6}{|c|}{$\geq 30^{\circ} \mathrm{C}$} \\
\hline PB-NO & $38.5,49$ & $40.3,51$ & $26.9,50$ & $27.3,50$ & $85.0,53$ & $74.7,47$ \\
\hline \multirow[t]{2}{*}{ PB-8 } & $95.5,51$ & $93.3,49$ & $119.0,59$ & $83.8,41$ & $158.3,53$ & $142.6,47$ \\
\hline & \multicolumn{6}{|c|}{$\geq 35^{\circ} \mathrm{C}$} \\
\hline PB-NO & $0.0, \mathrm{n} / \mathrm{a}$ & $0.0, \mathrm{n} / \mathrm{a}$ & $0.0, \mathrm{n} / \mathrm{a}$ & $0.0, \mathrm{n} / \mathrm{a}$ & $0.0, \mathrm{n} / \mathrm{a}$ & $0.0, \mathrm{n} / \mathrm{a}$ \\
\hline
\end{tabular}

${ }^{\mathrm{z}} \mathrm{PB}-\mathrm{NO}, \mathrm{PB}-4, \mathrm{~PB}-8$ = prebloom leaf removal of zero, four, and eight leaves, respectively.

${ }^{\mathrm{y} B e r r y}$ temperature logged 21 Aug. through 9 Oct. 2013, 24 Aug. through 16 Oct. 2014, and 12 Aug. through 5 Oct. 2015.

x 2014 and 2015 data include estimated data during missing observation periods.

$\mathrm{n} / \mathrm{a}=$ not applicable.

Table 4. Leaf removal and canopy side effect on estimated total berry phenolics and anthocyanins at harvest.

\begin{tabular}{|c|c|c|c|c|c|c|}
\hline & \multicolumn{3}{|c|}{ Prebloom } & \multirow[b]{2}{*}{ Treatment $^{2}$} & \multicolumn{2}{|c|}{ Postfruit set } \\
\hline & 2013 & 2014 & 2015 & & 2014 & 2015 \\
\hline & \multicolumn{6}{|c|}{ Total grape phenolics (au/g berry) } \\
\hline Treatment ${ }^{2}$ & & & & & & \\
\hline PB-4 & $83.4 \mathrm{a}$ & $94.3 \mathrm{a}$ & $78.5 \mathrm{~b}$ & PFS-6 & $55.7 \mathrm{a}$ & $66.6 \mathrm{a}$ \\
\hline PB-8 & $83.9 \mathrm{a}$ & $94.7 \mathrm{a}$ & $86.3 \mathrm{a}$ & & - & - \\
\hline \multicolumn{7}{|l|}{ Canopy side } \\
\hline East & 81.1 & 89.8 & 75.8 & & 51.3 & 62.9 \\
\hline Treatment & 0.0112 & $<0.0001$ & $<0.0001$ & & 0.0046 & 0.0105 \\
\hline Canopy side & NS & NS & NS & & NS & NS \\
\hline Treatment $\times$ canopy side & NS & NS & NS & & NS & NS \\
\hline & \multicolumn{6}{|c|}{ Total grape anthocyanins ( $\mathrm{mg} / \mathrm{g}$ berry) } \\
\hline \multicolumn{7}{|l|}{ Treatment $^{2}$} \\
\hline PB-NO & 0.94 & $1.11 \mathrm{~b}$ & $0.83 \mathrm{~b}$ & PFS-NO & 0.61 & $0.71 \mathrm{~b}$ \\
\hline West & 0.96 & 1.16 & 0.95 & & 0.62 & 0.73 \\
\hline \multicolumn{7}{|l|}{ Significance } \\
\hline Treatment & NS & 0.0013 & $<0.0001$ & & Ns & 0.0377 \\
\hline Canopy side & NS & NS & NS & & NS & NS \\
\hline Treatment $\times$ canopy side & NS & NS & NS & & NS & NS \\
\hline
\end{tabular}

${ }^{\mathrm{z}}$ PB-NO, PB-4, PB-8 = prebloom leaf removal of zero, four, and eight leaves, respectively; PFS-NO and PFS-6 = postfruit set removal of zero and six leaves, respectively.

${ }^{\mathrm{y}}$ Significance of treatment effects ( $\mathrm{NS}=$ not significant). Means in the same treatment group (columns) not sharing the same letter are significantly different at the 0.05 level based on adjusted $P$ values using Tukey's honestly significant difference test (prebloom experiment) and Student's $t$ test (postfruit set experiment, canopy side).

to 1700 HR (Fig. 2). Bimodal peaks in fruitzone $P A R$ were experienced from 0900 to $1100 \mathrm{HR}$ and again from 1500 to $170 \mathrm{HR}$ when leaves were removed from, but not when leaves remained in, fruit zones (Fig. 2). The bimodal fruit zone $P A R$ peaks were a function of greater incident radiation reaching the fruit zone in the morning and afternoon hours relative to those surrounding solar noon (1259-1317 HR over postveraison period at experimental vineyard), when the VSP canopy blocked fruit-zone radiation penetration. Similar fruit-zone $P A R$ patterns were reported in north/south-oriented, but not in northeast/southwest- or northwest/ southeast-oriented, VSP rows in the Breede River Valley in South Africa (Hunter et al., 2016). Fruit-zone $P A R$ values in the $P B-4$ and PB-8 plots of the current study were often well above $100 \mu \mathrm{mol} \cdot \mathrm{m}^{-2} \cdot \mathrm{s}^{-1}$, the in- cident radiation quantity that may not limit, and above which temperature has greater impact on, grape anthocyanin biosynthesis [Downey et al. (2006) and those cited within]. Row orientation, global position, climate, and fruit-zone management all affect diurnal patterns and intensities of fruit-zone radiation (Bergqvist et al., 2001; Buttrose et al., 1971; Spayd et al., 2002; Tarara et al., 2008; Yamane and Shibayama, 2006).

Berry temperature and ambient air temperature were similar among all treatments from dusk to dawn (average trends shown in Fig. 2; treatment-specific data not shown). Exposed berries were warmer than ambient temperature during the daytime, except when berries were shaded by foliage (Fig. 2). Maximum differences between ambient temperature and berry temperature on east canopy sides were recorded from 0900 to 1100
HR, whereas maximum differences on the west sides occurred from 1500 to $1700 \mathrm{HR}$. Those periods coincided with fruit-zone $P A R$ maxima of the respective canopy sides (Fig. 2). Point-in-time quantification of eastside and westside berry temperature extremes may therefore occur optimally between 0900 and $1100 \mathrm{HR}$ and 1500 and $1700 \mathrm{HR}$, respectively, in north/south-oriented VSP vineyard rows in the eastern United States. Grape clusters in high-wire training systems with trailing canopies would likely experience greater heat loads around solar noon relative to clusters in VSP systems.

Average logged berry temperature was 0.4 to $0.5{ }^{\circ} \mathrm{C}$ greater in PB-4 and PB- 8 plots when compared with $\mathrm{PB}-\mathrm{NO}$ plots and was not affected consistently by canopy side (data not shown). Average logged berry temperature (data not shown) was lower 

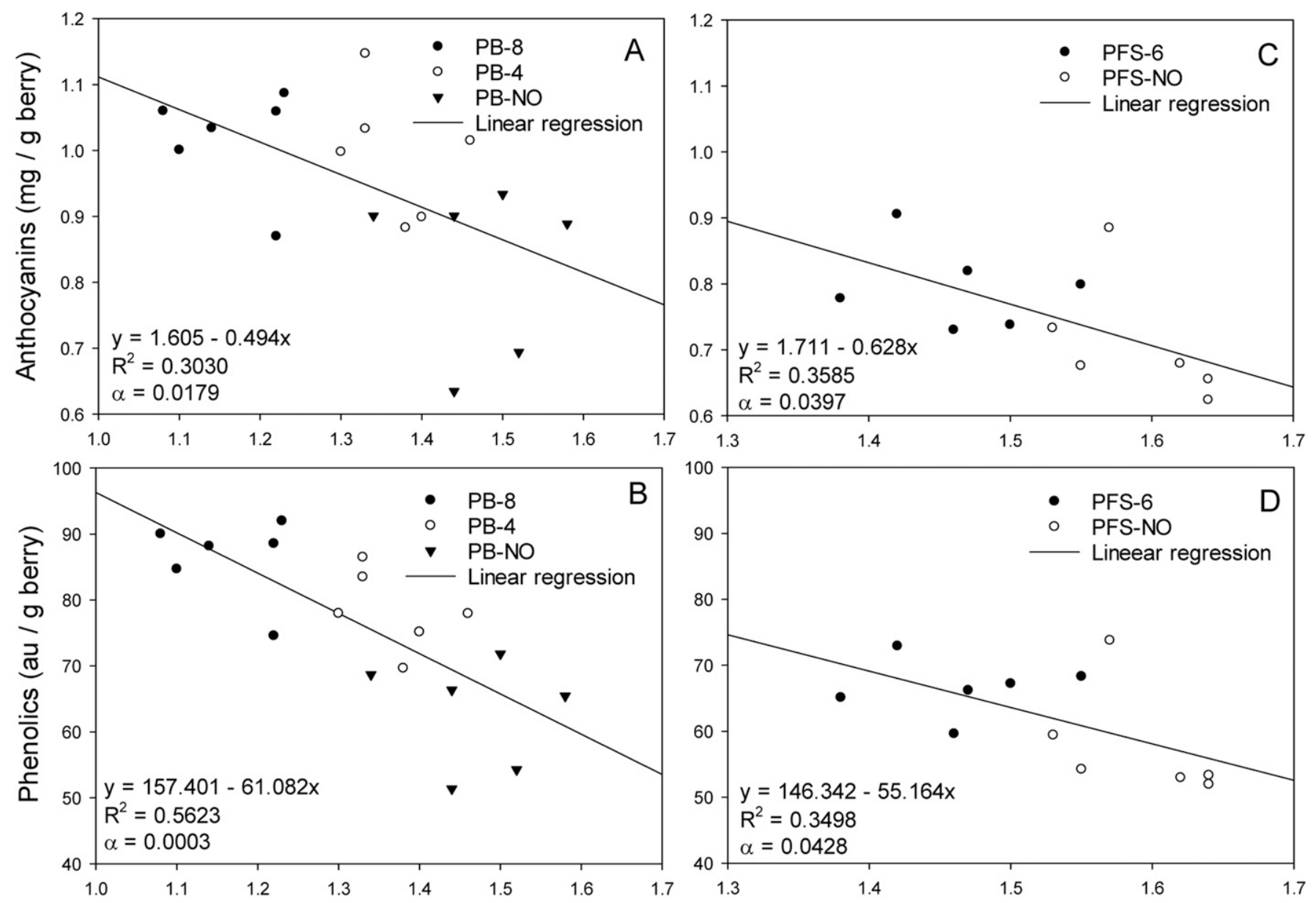

Berry weight $(\mathrm{g})$

Fig. 3. The linear relationship between harvest berry weight and total berry anthocyanins $(\mathbf{A}, \mathbf{C})$ and phenolics $(\mathbf{B}, \mathbf{D})$ in the prebloom (A, B) and postfruit set leaf removal experiments in 2015 (C, D). Each data point represents an average of 120 berries; $n=6$.

than average manually measured berry temperature (Table 2) - a probable function of our logging berry temperatures throughout cooler nighttime periods (Fig. 2). Maximum logged berry temperature was 3.8 to $5.2{ }^{\circ} \mathrm{C}$ greater in PB-4 and PB- 8 plots when compared with PB-NO plots, but was affected less consistently by canopy side over 2013 to 2015 (data not shown). Our findings again contrast those reported in arid regions, where westside grapes were documented to be consistently warmer than eastside grapes in north/south-oriented rows (Bergqvist et al., 2001; Spayd et al., 2002; Tarara et al., 2008). Logged berry temperatures followed ambient air temperature (Fig. 2) and growing degree day trends as reported before at this site (Hickey and Wolf 2018); 2015 was the warmest growing season and 2013 was generally warmer than 2014 .

Relatively greater ambient air temperature was required 1) to heat $\mathrm{PB}-\mathrm{NO}$ berries to $\geq 30{ }^{\circ} \mathrm{C}$ when compared with PB-4 and PB-8 berries, 2) to heat shaded berries (east in the afternoon, west in the morning) to $\geq 30{ }^{\circ} \mathrm{C}$ when compared with sunlit berries (east in the morning, west in the afternoon), and 3) to heat sunlit PB- 4 and PB- 8 berries (east in the morning, west in the afternoon) to $\geq 30$ and
$35{ }^{\circ} \mathrm{C}$ during the hours surrounding solar noon when compared with hours before and after solar noon (data not shown). These data illustrated that direct radiation was generally required for berry temperatures to exceed $35{ }^{\circ} \mathrm{C}$, as reported before (Tarara et al., 2008). Following postveraison temperature trends, berry temperatures were $\geq 30$ or $35^{\circ} \mathrm{C}$ for relatively greater amounts of time during the postveraison period of 2015 relative to the same period in 2013 and 2014 (Table 3). Berries spent more time at $\geq 30$ or $35^{\circ} \mathrm{C}$ in PB-4 and PB-8 compared with PB-NO.

Spectrophotometric estimation of total grape phenolics and anthocyanins. Total estimated grape phenolics increased consistently by PB-4, PB- 8 , and PFS- 6 relative to no leaf removal, but were unaffected by canopy side (Table 4). Berry weight was related inversely to phenolics in 2015 only (Fig. 3; 2013 and 2014 data not shown), whereas LLN was related inversely, and CEFA related positively, to phenolics in all 3 years of the prebloom experiment $\left(R^{2}\right.$ range, $0.2211-0.5715$ for $L L N ; R^{2}$ range, 0.2483-0.4816 for CEFA) (data not shown). These trends suggest that greater berry phenolics were a result of both reduced berry size and greater sunlight penetration to clusters, and possibly individual berries within a given cluster.

Vine management effects on grape flavonoids have been widely researched because certain flavonoids, including anthocyanins, tannins, and flavonols, affect red wine attributes, including color density and astringency [Downey et al. (2006) and those cited within]. Anthocyanins and flavonols are more sensitive to changes in light and temperature than tannins (Downey et al., 2006), and these two flavonoids likely contributed to the increased total phenolic concentration in exposed, relative to shaded, grapes. Total phenolics have also shown a positive relationship to wine quality grades, including for 'Cabernet Sauvignon' (Mercurio et al., 2010), although that work encouraged a multivariate analysis of tannins, phenolics, and color to obtain more precise estimates of wine quality for market grading. We submit that well-exposed 'Cabernet Sauvignon' grapes should produce superior wines to shaded fruit in mid-Atlantic vineyards from the standpoint of phenolics and color. The caveat to this generalization, however, is that excessive exposure of developing fruit might accentuate wine astringency undesirably as a result of increased phenolic concentrations 
[Kennedy (2008) and those cited within]. Cabernet franc wines made from highly exposed grapes in the same region had greater color intensity, but also greater astringency relative to minimally exposed grapes (Hickey et al., 2018). Further canopy management research could help fine-tune fruit exposure goals under the variable climate conditions found across the eastern United States.

Fruit-zone leaf removal treatments increased total estimated grape anthocyanins inconsistently relative to no leaf removal treatments (Table 4). Like phenolics, anthocyanins were related inversely to berry weight in 2015 only (Fig. 3; 2013 and 2014 data not shown) and were related inconsistently to LLN and CEFA across experiments and years (data not shown). Berry temperatures greater than the provisional thresholds of either 30 or $35^{\circ} \mathrm{C}$ can compromise grape anthocyanins [Buttrose et al., 1971; Downey et al., 2006 (and those cited within); Spayd et al., 2002; Tarara et al., 2008], perhaps as a result of impaired enzyme activity in the flavonoid biosynthetic pathway ending in anthocyanin biosynthesis (Yamane and Shibayama., 2006). Low nighttime temperature is beneficial for anthocyanin accumulation (Mori et al., 2005), especially during the first 2 weeks after veraison onset (Gaiotti et al., 2018). It is unclear whether transient hightemperature episodes or sustained periods of excessive berry temperatures are of greater detriment to the inhibition of anthocyanin accumulation. It is also unclear when grapes are most sensitive to the negative effects of high temperatures on anthocyanin biosynthesis. Addressing such issues was beyond the scope of this study. When averaged over three postveraison periods, even the greatest sums of time that berries spent at $\geq 30$ or $35^{\circ} \mathrm{C}$ in our study $\left(124.3 \mathrm{~h} \geq 30^{\circ} \mathrm{C} ; 17.3 \mathrm{~h} \geq\right.$ $35^{\circ} \mathrm{C}$; data not shown) were relatively less than another report of postveraison berry temperature sums averaged over three postveraison periods $\left(166 \mathrm{~h}>30^{\circ} \mathrm{C}\right.$ and $89 \mathrm{~h}>$ $35^{\circ} \mathrm{C}$ ) when grape anthocyanin concentrations were reduced (Tarara et al., 2008).

As with phenolics, anthocyanins were unaffected by canopy side (Table 4). There was little difference in the duration that eastside and westside berries were at $\geq 30$ and $35{ }^{\circ} \mathrm{C}$ during the postveraison periods (Table 3). In fact, eastside berries tended to spend slightly longer periods above those thresholds compared with westside berries. In contrast, westside grapes were warmer than eastside grapes in the San Joaquin Valley of California (Bergqvist et al., 2001; Spayd et al., 2002; Tarara et al., 2008), and spent $52-70 \mathrm{~h}$ more at $>35^{\circ} \mathrm{C}$ compared with eastside grapes in Prosser, WA (Spayd et al., 2002; Tarara et al., 2008). The limited difference in the temperature extremes experienced by eastside and westside berries in our study was likely a result of attenuated $P A R$ after solar noon. Cloud sky coverage occurs with greater frequency in humid - relative to arid-regions, and therefore may generally reduce the differences in berry temperature on east and west canopy sides of north/southoriented rows in humid regions. Calling the west side of the canopy "hot" may not be accurate in humid regions. Rather, canopy side effect on berry temperature is a function of diurnal temperatures and radiation patterns, and therefore is vintage dependent.

\section{Conclusion}

Fruit-zone leaf removal to zero leaf layers increased grape phenolics and affected anthocyanins inconsistently. Canopy side had no bearing on these results. Diurnal radiation patterns attenuated the temperature differential between exposed grapes positioned on the morning (east) and afternoon (west) sides of the northeast/southwest-oriented canopies. In effect, restricting leaf-thinning practices to the east side of generally north/southoriented canopies for fear of adversely affecting fruit color development might be unnecessarily conservative. Taken together with previously reported data, a more liberal fruit-zone leaf removal can reduce bunch rot without affecting red wine quality potential negatively. Future work should evaluate vineyard fruit-zone management in locales anticipated to experience greater radiation and heat load than the Shenandoah Valley AVA of Virginia.

\section{Literature Cited}

Austin, C.N. and W.F. Wilcox. 2011. Effects of fruit zone leaf removal, training systems, and irrigation on the development of grapevine powdery mildew. Amer. J. Enol. Viticult. 62:193-198

Bergqvist, J., N.K. Dokoozlian, and N. Ebisuda. 2001. Sunlight exposure and temperature effects on berry growth and composition of Cabernet Sauvignon and Grenache in the central San Joaquin Valley of California. Amer. J. Enol. Viticult. 52:1-7.

Buttrose, M.S., C.R. Hale, and W.M. Kliewer. 1971. Effect of temperature on the composition of 'Cabernet Sauvignon' berries. Amer. J. Enol. Viticult. 22:71-75.

Cola, G., O. Failla, and L. Mariani. 2009. BerryTone: A simulation model for the daily course of grape berry temperature. Agr. For. Meteorol. 149:1215-1228.

Diago, M.P., B. Ayestaran, Z. Guadalupe, S. Poni, and J. Tardaguila. 2012. Impact of prebloom and fruit set basal leaf removal on the flavonol and anthocyanin composition of Tempranillo grapes. Amer. J. Enol. Viticult. 63:367-376.

Di Profio, F., A.G. Reynolds, and A. Kasimos. 2011. Canopy management and enzyme impacts on Merlot, Cabernet franc, and Cabernet Sauvignon: II. Wine composition and quality. Amer. J. Enol. Viticult. 62:152-168.

Dokoozlian, N.K. and W.M. Kliewer. 1996. Influence of light on grape berry growth and composiiton varies during fruit development. J. Amer. Soc. Hort. Sci. 121:869-874.

Downey, M.O., N.K. Dokoozlian, and M.P. Krstic. 2006. Cultural practice and environmental impacts on flavonoid composition of grapes and wine: A review of recent research. Amer. J. Enol. Viticult. 57:257-268.

Dry, P. and B. Coombe (eds.). 2004. Viticulture 1: Resources. 2nd ed. Revised version of grape- vine growth stages: The modified E-L system. Winetitles, Adelaide, Australia.

English, J.T., C.S. Thomas, J.J. Marois, and W.D. Gubler. 1989. Microclimates of grapevine canopies associated with leaf removal and control of Botrytis bunch rot. Phytopathology 79:395401.

Faust, J.E. and J. Logan. 2018. Daily light integral: A research review and high-resolution maps of the United States. HortScience 53:1250-1257.

Frioni, T., S. Zhuang, A. Palliotti, P. Sivilotti, R. Falchi, and P. Sabbatini. 2017. Leaf removal and cluster thinning efficiencies are highly modulated by environmental conditions in cool climate viticulture. Amer. J. Enol. Viticult. 68:325-335

Gaiotti, F., C. Pastore, I. Filippetti, L. Lovat, N. Belfiore, and D. Tomasi. 2018. Low night temperature at veraison enhances the accumulation of anthocyanins in Corvina grapes (Vitis vinifera L.). Scientific Rpt. 8:8719.

Giusti, M.M. 2001. Characterization and measurement of anthocyanins by UV-visible spectroscopy, p. 19-32. In: R.E. Wrolstad (ed.). Current protocols in food analytical chemistry. Wiley, Hoboken, NJ.

Hed, B., H.K. Ngugi, and J.W. Travis. 2015. Shortand long-term effects of leaf removal and gibberellin on Chardonnay grapes in the Lake Erie region of Pennsylvania. Amer. J. Enol. Viticult. 66:22-29.

Hickey, C.C., M.T. Kwasniewski, and T.K. Wolf. 2018. Leaf removal effects on Cabernet franc and Petit Verdot. II. Grape carotenoids, phenolics, and wine sensory analysis. Amer. J. Enol. Viticult. doi: 10.5344/ajev.2018.17107.

Hickey, C.C. and T.K. Wolf. 2018. Cabernet Sauvignon responses to prebloom and postfruit set leaf removal in Virginia. Catalyst 2:24-34.

Hunter, J., O.T. de Villiers, and J.E. Watts. 1991. The effect of partial defoliation on quality characteristics of Vitis vinifera L. cv. Cabernet Sauvignon grapes II: Skin colour, skin sugar and wine quality. Amer. J. Enol. Viticult. 42:13-18.

Hunter, J.J., C.G. Volschenk, and R. Zorer. 2016. Vineyard row orientation of Vitis vinifera L. cv. Shiraz/101-14 Mgt: Climatic profiles and vine physiological status. Agr. For. Meteorol. 228229:104-119.

Kennedy, J.A. 2008. Grape and wine phenolics: Observations and recent findings. Cien. Inv. Agr. 35:107-120.

Kotseridis, Y., A. Georgiadou, P. Tikos, S. Kallithraka, and S. Koundouras. 2012. Effects of severity of post-flowering leaf removal on berry growth and composition of three red Vitis vinifera L. cultivars grown under semiarid conditions. J. Agr. Food Chem. 60:6000-6010.

Lee, J., R.W. Durst, and R.E. Wrolstad. 2005. Determination of total monomeric anthocyanin pigment content of fruit juices, beverages, natural colorants, and wines by the $\mathrm{pH}$ differential method: Collaborative study. J. AOAC Intl. 88:1269-1278.

Mercurio, M.D., R.G. Dambergs, D. Cozzolino, M.J. Herderich, and P.A. Smith. 2010. Relationship between red wine grades and phenolics: 1. Tannin and total phenolics concentrations. J. Agr. Food Chem. 58:12313-12319.

Meyers, J.M. and J.E. Vanden Heuvel. 2008. Enhancing the precision and spatial acuity of point quadrat analysis via calibrated exposure mapping. Amer. J. Enol. Viticult. 59:353363.

Mori, K., S. Sugaya, and H. Gemma. 2005. Decreased anthocyanin biosynthesis in grape 
berries grown under elevated night temperatures. Scientia Hort. 105:319-330.

NASA. 1999. NF-207: The earth science enterprise series: Clouds and the energy cycle. National Aeronautics and Space Administration, Goddard Space Flight Center, Greenbelt, MD.

NASA Earth Observations. 2018. Cloud fraction of Earth. 7 Sept. 2018. <http://neo.sci.gsfc.nasa. gov/view.php?datasetId=MYDAL2_M_CLD_ FR\&year $=2013>$.

Natural Resources Conservation Service. 1987. US Geological Survey, Frederick County, VA. Dec. 2018. <http://websoilsurvey.nrcs.usda. gov>.

Razungles, A.J., R.L. Baumes, C. Dufour, C.N. Sznaper, and C.L. Bayonove. 1998. Effect of sun exposure on carotenoids and C13norisoprenoid glycosides in Syrah berries (Vitis vinifera L.). Sci. Aliments 18:361-373.

Reynolds, A. and T.K. Wolf. 2008. Grapevine canopy management, p. 124-134. In: T.K. Wolf (ed.). Wine grape production guide for eastern North America. Natural Resource, Agriculture, and Engineering Service (NRAES) Cooperative Extension, Ithaca, NY.
Ryona, I., B.S. Pan, D.S. Intrigliolio, A.N. Lakso, and G.L. Sacks. 2008. Effects of cluster light exposure on 3-isobutyl-2-methoxypyrazine accumulation and degradation patterns in red wine grapes (Vitis vinifera L. cv. Cabernet Franc). J. Agr. Food Chem. 56:1083810846.

Smart, R. and M. Robinson. 1991. Sunlight into wine: A handbook for winegrape canopy management. Winetitles, Adelaide, Australia.

Spayd, S., J.M. Tarara, D.L. Mee, and J.C. Ferguson. 2002. Separation of sunlight and temperature effects on the composition of Vitis vinifera cv. Merlot berries. Amer. J. Enol. Viticult. 53:171-182.

Staff, S.L., D.C. Percival, J.A. Sullivan, and K.H. Fisher. 1997. Fruit zone leaf removal influences vegetative, yield, disease, fruit composition, and wine sensory attributes of Vitis vinifera $\mathrm{L}$. 'Optima' and 'Cabernet franc'. Can. J. Plant Sci. 77:149-153.

Takos, A.M., F.W. Jaffe, S.R. Jacob, J. Bogs, S.P. Robinson, and A.R. Walker. 2006. Lightinduced expression of $M Y B$ gene regulates anthocyanin biosynthesis in red apples. Plant Physiol. 142:1216-1232.

Tarara, J., J.M. Lee, S.E. Spayd, and C.F. Scagel. 2008. Berry temperature and solar radiation alter acylation, proportion and concentration of anthocyanins in Merlot grapes. Amer. J. Enol. Viticult. 59:235-247.

Verzera, A., G. Tripodi, G. Dima, C. Condurso, A Scacco, F. Cincotta, D.M.L. Giglio, T. Santangelo, and A. Sparacio. 2016. Leaf removal and wine composition of Vitis vinifera L. cv. Nero d'Avola: The volatile aroma constituents. J. Sci. Food Agr. 96:150-159.

Weaver, R.J. and S.B. McCune. 1960. Influence of light on color development in Vitis vinifera grapes. Amer. J. Enol. Viticult. 11:179-184.

Wolf, T.K., R.M. Pool, and L.R. Mattick. 1986. Responses of young Chardonnay grapevines to shoot tipping, ethephon, and basal leaf removal. Amer. J. Enol. Viticult. 37:263268.

Yamane, T. and K. Shibayama. 2006. Effects of changes in the sensitivity to temperature on coloration of ‘Aki Queen' grape berries. J. Jpn. Soc. Hort. Sci. 75:458-462. 